\title{
Medical students give lower marks to training in some specialties
}

\author{
— Cite as: CMAJ 2019 October 28;191:E1204. doi: 10.1503/cmaj.1095826
}

Posted on cmajnews.com on Oct. 9, 2019

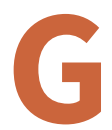

raduating Canadian medical students are generally happy with the quality of their training, according to a survey by the Association of Faculties of Medicine of Canada (AFMC). However, more than 1 in 10 ranked their training in certain specialties as fair or poor.

Of the 2878 medical students eligible to graduate this year in Canada, $67.1 \%$ (1931) responded to the AFMC questionnaire. About two-thirds rated their overall medical education as very good or excellent, but they were less satisfied with their training in some specialties. Just over $16 \%$ rated their training in surgery and obstetrics and gynecology as fair or poor, while $12.9 \%$ gave similarly low marks to pediatrics and $11.6 \%$ to psychiatry.

A lack of timely feedback in some specialties may be part of the problem. More than 1 in 10 graduating students disagreed that they received feedback early enough to improve their performance in obstetrics and gynecology (10.5\%) and surgery (13.2\%).

More than a quarter of graduating students also reported receiving inadequate training in health policy (29.6\%), health care systems $(25.9 \%)$, law and medicine (28.4\%), and complementary and alternative medicine (31.1\%). Nearly 1 in 5 said they lacked confidence in their ability to counsel patients who use alternative therapies; and nearly 1 in 10 said they lacked confidence using technology to access information during patient encounters.

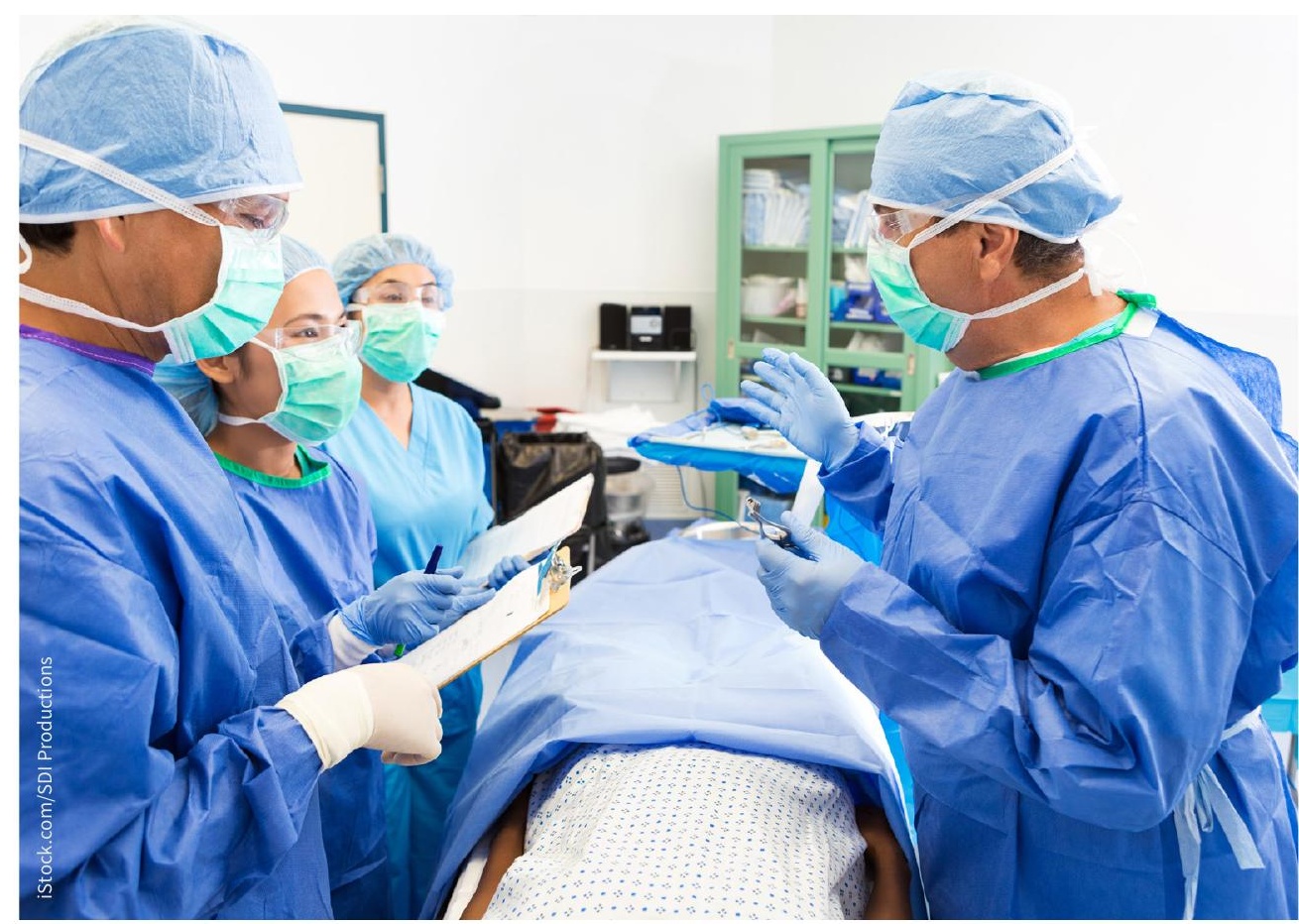

More than 1 in 10 graduating medical students ranked their training in obstetrics, surgery, pediatrics and psychiatry as fair or poor.

Overall, however, $95.4 \%$ of graduating students felt confident they had the clinical skills required to begin residency. Most also reported being satisfied or very satisfied with career planning services $(77.7 \%)$ and knowing procedures for reporting mistreatment (83.5\%).

Nearly 3 in 5 students indicated they personally experienced mistreatment from faculty, nurses, residents, staff or other students during their training. Among the most common types of mis- treatment, 2 in 5 said they were publicly humiliated at least once and nearly a quarter were the target of sexist remarks.

Meanwhile, students were less positive about the wellness supports on offer at their schools; 1 in 4 were dissatisfied or very dissatisfied with programs to promote effective stress management, a balanced lifestyle and overall well-being, up from 1 in 5 last year.

\section{Lauren Vogel, CMAJ}

